\title{
Lateral Extrusion of Spur gears with Involute Profile: Finite Element Analysis and Experimental Investigation
}

\author{
U.C. Paltasingh ${ }^{1 *}$, S.K. Sahoo ${ }^{2}$, P.R. Das ${ }^{3}$, K.C. Nayak $^{2}$, S. Potnuru ${ }^{2}$ \\ ${ }^{1}$ (Department of Mechanical Engg, Padmanava College of Engg, Rourkela-769002,Odisha, India, \\ ${ }^{2}$ (Department of Mechanical Engg, NIT Rourkela, 769008, Odisha, India, \\ ${ }^{3}$ (Department of Mechanical Engg, VSSUT Burla, 768018, Odisha, India,
}

\begin{abstract}
Now a days, manufacturing of machine components with complex flange geometry or segmented protrusions which are very difficult to produce by the conventional forging, can be easily produced by lateral extrusion. Because of the low machining cost, reduced material waste, improved mechanical properties and subsequent increase in the industrial demand of these parts, has accelerated the progress of research in this field. So this paper presents the experimental and dynamic simulation study of lateral extrusion of spur gears with involute tooth profile in terms of load requirement, die filling and material flow. Three dimensional finite element analyses are carried out to investigate the effective stress and strain, die filling, flow patterns and prediction of extrusion loads. Series of experiment has been carried using tellurium lead with three sets of die profile. The comparison between the simulation and the experimental results show good agreement.
\end{abstract}

Keywords: - Extrusion load, Finite element, Flow pattern, Strain effective, Stress effective

\section{INTRODUCTION}

The lateral extrusion also called radial extrusion or injection forging is an important branch of the extrusion process. In this process the cylindrical solid or tubular billet contained in the chamber is pressed by single or multiple opposite simple punches, causing the metal to flow radially through a fixed die cavity. A thorough review of the literature was published by Balendra et al. [1] under the name of "injection forging". It is an often used forming process amongst the different metal forming operations and its industrial history dates back to the 18th century [2]. The process of precision gear forging has been developed long back because of its advantages of giving high production rates, improved strength and surface finish [3-8]. The precision forging of spline and gear forms were studied by Chitkara and Bhutta [9], Chitkara and Yohngjo [10] and Hsu [11]. They predicted the load requirement and the metal flow during the closed die forging of spline and spur gear form of straight tapered tooth profile by the upper bound method. Choi et al. [12, 13] and Cho et al. [14] also used an involute tooth profile instead of the tapered profile to obtain a more realistic solution in their upper bound analysis. Finite element analysis (FEA) of precision forging of spur gear has been done by Alves et al. [15]. Balendra $[16,17]$ have studied effect of process parameters on metal flow and load requirement for complete protrusion. Chitkara [18] presented an analysis of an external spline having profiled teeth, which are produced by the lateral extrusion, by using the upper method to predict the load and mode of deformation. In the lateral extrusion of spur gears, the bottom die is similar to that used in closed die forging but the upper die is a simple flat-faced circular punch and has no teeth protrusion on its periphery. Therefore, the design of the die set for lateral extrusion is simpler than that for closed die forging for the same product. This simplicity on the side of the upper die will allow to reduce the time and cost of die production [19]. Can et al. [20] have conducted series of experiments on lateral extrusion of splines and gear like elements in terms of load requirement and die filling. They proposed various mathematical models using upper bound techniques to investigate the load requirements and effect of process parameters.

By use of this method, subsequent operations like machining can be reduced. The most important characteristic features of this process are that it offers better die filling and consumes low energy for complex parts when compared with the conventional forging processes. Although the closed die forging of spur gears and gear like elements and splines have been investigated extensively, little work has been carried out on the production of the spur gears by the lateral extrusion with involute profile.

Keeping in view of the work done by the above researchers, this paper presents an experimental and FEM study to investigate the influence of the number of teeth and the teeth thickness on forming load, die filling and flow pattern. The three dimensional FE analyses has been used to investigate the effect of some important geometrical parameters such as billet height, die volume as well as process condition such as friction on the process using DEFORM 3D. The results of FEM are compared with experimental results in terms of Peak load and teeth thickness with varying number of teeth and found to be in good agreement to some extent. 


\section{LATERAL EXTRUSION PROCESS}

The principle of the lateral extrusion process and the geometrical parameters utilized in this work has been showed in Fig. 1. A cylindrical billet is driven down by the punch, against the lower flat die, which is stationary, extruding it radially into the die cavity. Fig. 1 shows the initial (left side) and final (right side) position of the punch in the process while the direction of material flow is perpendicular to punch movement direction.

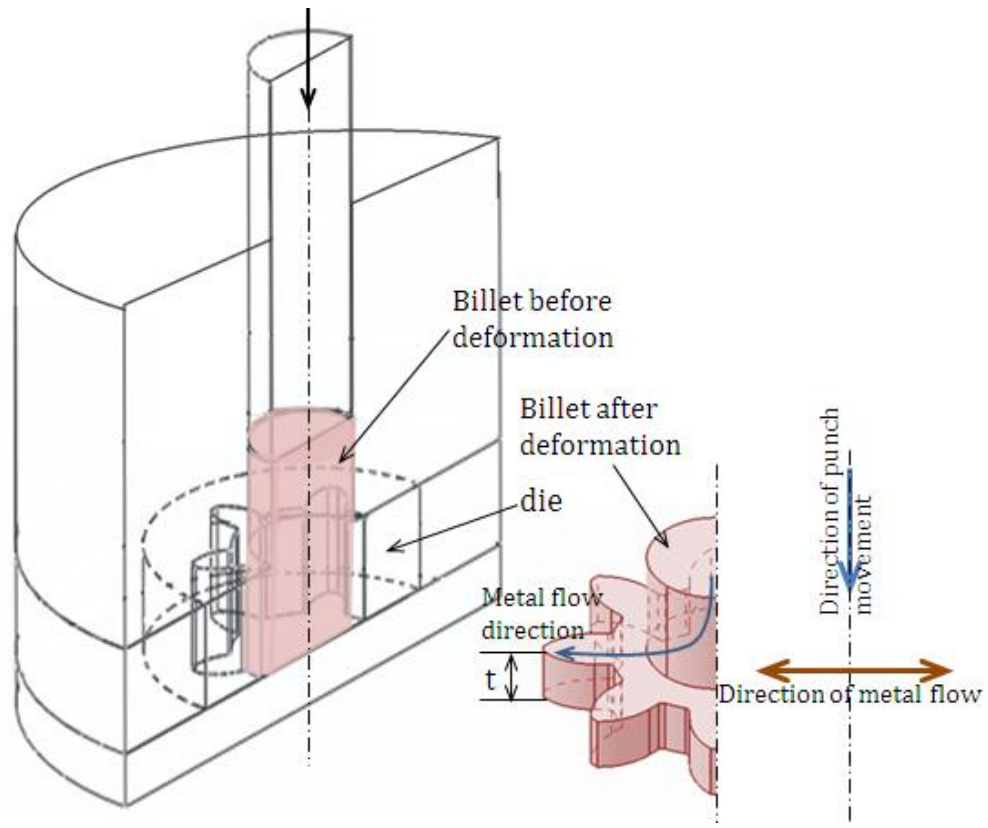

Figure 1 Schematic view of lateral extrusion

\subsection{FE Modeling}

\section{FINITE ELEMENT ANALYSIS}

In finite element modeling, lateral extrusion of spur gears having 4teeth, 6teeth and 8teeth with variable teeth thickness are investigated. The process is modeled as three dimensional finite element analyses using DEFORM $^{\mathrm{TM}}$ 3D software [21].

The finite element code uses an updated Lagrangian procedure based on the flow formation approach. This software uses direct iteration method and the Conjugate-Gradient method to solve the nonlinear equations. In the solution procedure, the direct iteration method is used to generate a suitable initial estimate for the Conjugate-Gradient method, which is further used to obtain a rapid final convergence with velocity error of 0.005 and force error of 0.05 . During the simulations, the billet is assumed to be rigid plastic, and the die, the container as well as the flow guide are certainly rigid. The four-node tetrahedron elements are used. The isothermal condition is adopted in the finite element simulations. The flow stress characteristic of lead is modeled using equation 1 .

$\bar{\sigma}=A \bar{\epsilon}^{b} \bar{\epsilon}^{C}+D$

Putting the value of $c$ and $D=0$ in Equation (1), we get,

$\bar{\sigma}=A \bar{\epsilon}^{b}$

Where $A, D=$ constant, $\bar{\epsilon}$ and $\vec{\epsilon}$ are the strain and strain rate respectively, $\mathrm{b}$ and $\mathrm{c}$ are strain exponent and strain rate exponent respectively

\subsection{Application to present problem}

In this study, plastic flow of metal through flat dies for lateral extrusion process takes place and is used to obtain involute profile spur gears with round shaft. This process can be divided into two stages. In the first stage, initial compression and the upsetting take place simultaneously until deformed material begins to make contact with the die wall. In the second stage, extrusion take place and material flow perpendicular to the punch movement in radial direction until filling of the extrusion die cavity. Die punch setup for this lateral extrusion in simulation modelling to produce the spur gear is shown in Fig. 2. 


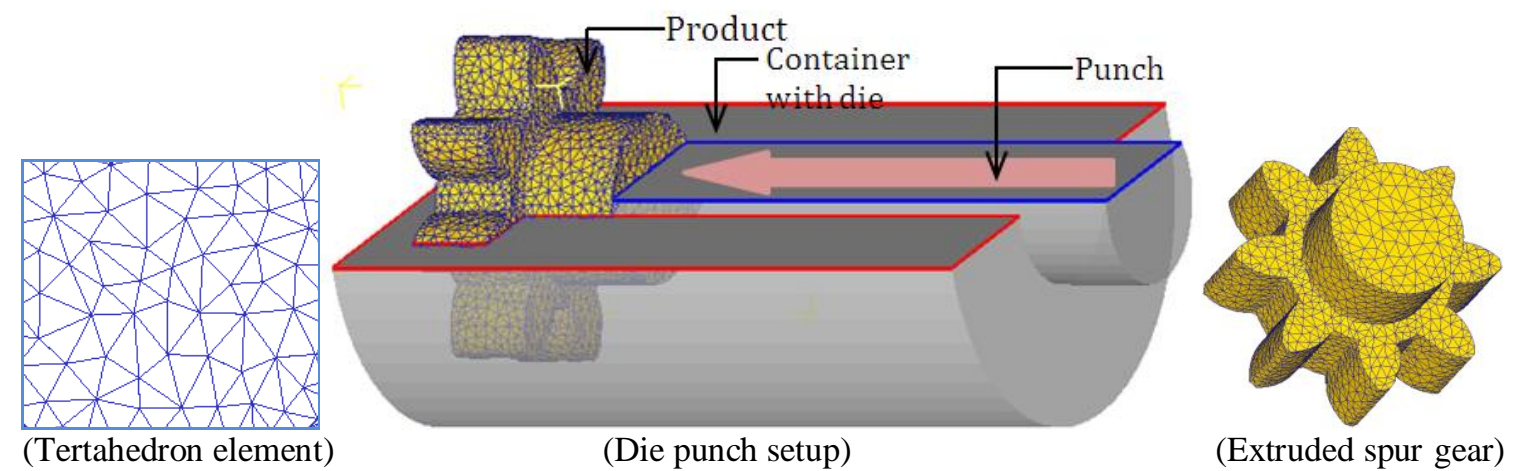

Figure 2 Pictorial view of die punch setup used for simulation process

It is understood from the experiments (experimental detail given in subsequent section) that the last stage of the process requires maximum load for a steady state extrusion to obtain the product. This maximum load is very much important for die design. The present FE analysis focuses on this final stage of steady state extrusion. Die filling at different stages and corresponding flow patterns have also been analyzed. It is assumed that the centroid of the die orifice lies on the billet axis.

The interfaces between the billet and the die, container, and the flow guide have a constant friction factor $\mathrm{m}$, which is set to be 0.21 to correspond to the condition of cold forming. The billet is divided into about 30,000 elements. In order to reduce the simulation time, the die cavity is filled with the billet before extrusion. The temperatures of all the objects are set as $30^{\circ} \mathrm{C}$. Following assumptions are made in the simulation procedure: that is (1) the die material is set as a rigid object. (2) The billet material used in this simulation is solid tellurium lead and modeled as a rigid-plastic material with Von Misses yield criterion. (3) The friction factors between the workpiece and die are kept constant which is obtained from ring test. (4) Global remeshing criterion and logarithmic interpolation.

\section{EXPERIMENTAL ANALYSIS}

\subsection{Experimental setup}

Experiments are conducted on a universal testing machine (INSTRON ${ }^{\circledR} 600 \mathrm{KN}$ ) shown in Fig. 3 with constant ram speed of $1 \mathrm{~mm} / \mathrm{min}$. The apparatus mainly consists of four parts namely, the container having a cylindrical extrusion chamber of $30 \mathrm{~mm}$ diameter, the extruding punch of same diameter, the die holder, and the supporting block for the die holder. Two flat plates of $5 \mathrm{~mm}$ thick and profile same as that of the die are used to reduce the die thickness to subsequently $15 \mathrm{~mm}$ and $10 \mathrm{~mm}$ are shown in Fig. 4. The commercial lead billets of $\varnothing 32 \mathrm{~mm}$ were casted and machined to the required length of $\varnothing 30 \mathrm{~mm}$. The specimens are cleaned with acetone so as to provide a similar friction condition. The inside surfaces of the extrusion chamber are flame hardened to reduce frictional wear. The flat dies used in the present series of experiments are made of two split halves for easy removal of the extruded product. All the experiments are conducted on three sets of dies.

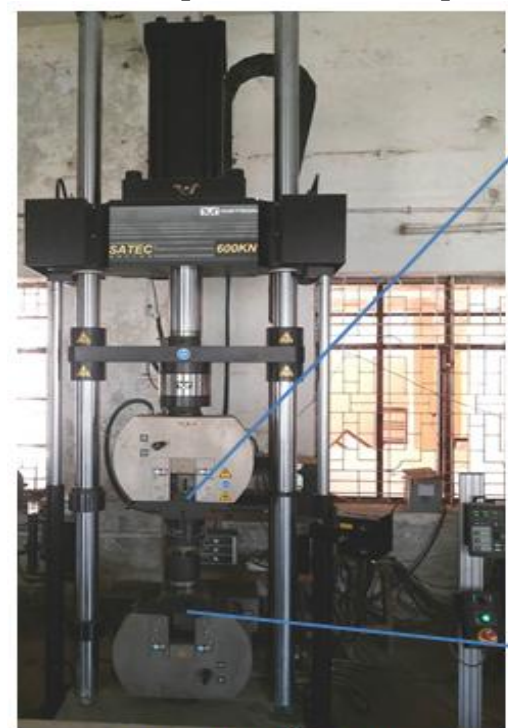

Experimental setup

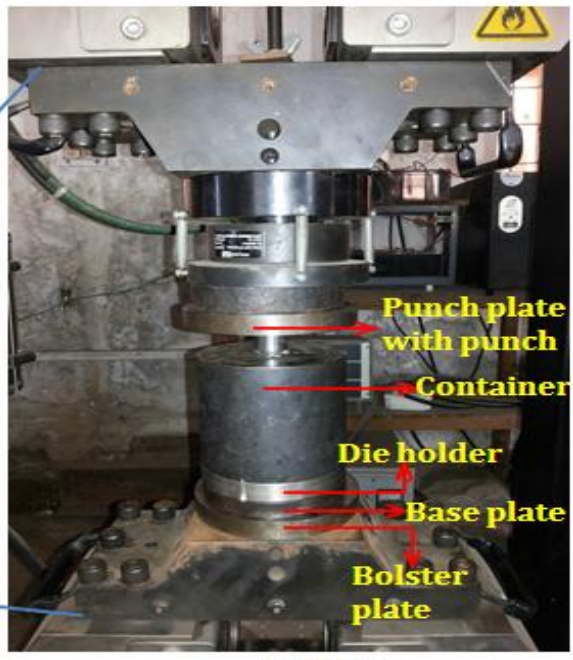

Test rig

Figure 3 Photgraphic view of experimental setup 


\subsection{Split dies used for spur gears}

The dies used in the present series of experiments are made of two halves for easy removal of the extruded product as shown in Fig. 4. The orifices are so made that the respective centers of gravity lie on the billet axis. These dies are produced by wire cut EDM from $20 \mathrm{~mm}$ thick flat plates oil- hardened and nonshrinking EN31 hot rolled tool steel. After machining, each die set is first normalized at a temperature of $930^{\circ} \mathrm{C}$ in a reducing atmosphere and then hardened by quenching in oil from the above temperature to attain a hardness, $\mathrm{R}_{\mathrm{c}}$, of 60-65. Packing plates are made by the same process as dies (Fig. 4). These plates are used for thickness variation of spur gear shape lateral extrusion.

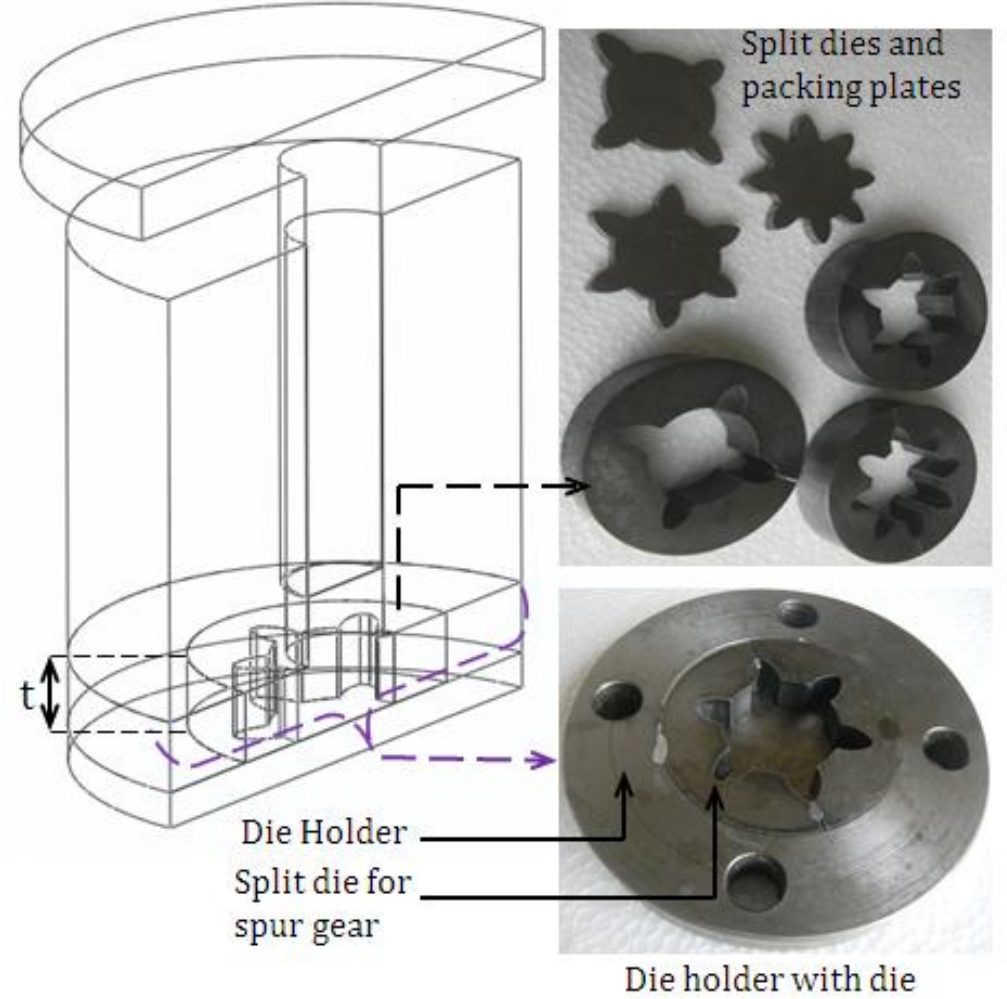

Figure 4 Split dies and packing plates with assembly

\subsection{Process variables}

There are several geometrical and experimental variables that influence the forming load and material flow into the die cavity. The major process variables are identifies as the number of teeth of spur gear, thickness of teeth and friction coefficient $(\mathrm{m})$ between die and workpiece. These parameters are summarized in Table 1. In order to investigate the influence of these variables on the forming load and material flow, FEM analysis and experimental tests were performed using different values of process variables.

Table 1 Process variables

\begin{tabular}{|c|c|c|}
\hline Nos. of teeth & Teeth thickness, $\mathrm{t}(\mathrm{mm})$ & Friction factor, $\mathrm{m}$ \\
\hline 4 & $10,15,20$ & \multirow{2}{*}{0.21} \\
\hline 6 & $10,15,20$ & \\
\hline 8 & $10,15,20$ & \\
\hline
\end{tabular}

\subsection{Experimentation}

Initially the die sets, the die holder and the inside faces of the extrusion chamber are cleaned with carbon tetrachloride. The two-halves of the die set are then push-fitted into the die holder and the total assembly is secured by screwing the four bolts. The full assembly is then placed on the lower table of the universal testing machine (Fig. 3). For carrying out an extrusion test, the sides of the lead specimen excepting the bottom face are smeared with grease (commercially available SKF LGMT 3IN1 general purpose grease) and the specimen was placed inside the extrusion chamber. For the lubrication, the friction factor is found to be 0.21 from ring test. The punch is then inserted into its position. After centering the apparatus under the machine lower table, the machine is started and the extrusion process was continued. The punch movement is adjusted to approximately 1 $\mathrm{mm} / \mathrm{min}$ and punch load is recorded at every $1 \mathrm{~mm}$ of punch travel. Extrusion is continued till the specified 
punch movement reaches. At this point the machine is stopped and the test is terminated. The die-punch set is de-assembled to push out the product from the die holder. Experiments are conducted for three different thicknesses $(20 \mathrm{~mm}, 15 \mathrm{~mm}$ and $10 \mathrm{~mm})$ as well as different number of teeth $(4,6$ and 8 teeth). Solid cylindrical specimen of lead with $\Phi 30 \mathrm{~mm} \times 45 \mathrm{~mm}(\mathrm{H} / \mathrm{D}=1.5)$ are used to obtain the stress-strain curve by a compression test at room temperature. By maintaining the compression rate same as that in experiment, the average flow stress of the material is found to be $27.7 \mathrm{MPa}$.

\subsection{Simulation results}

\section{RESULTS AND DISCUSSION}

Simulations were carried out with 4 teeth, 6 teeth and 8 teeth spur gears with three different thicknesses $(10,15$ and $20 \mathrm{~mm})$ in two stages. In the first stage, effective strain and stress were analyzed in each case at constant teeth thickness of $15 \mathrm{~mm}$. The results obtained is shown in the Fig. 5 (a, b, c, d. e and f). The figure indicates that the strain is almost uniform throughout the deformation and lies within the range of 0 to $5.56 \mathrm{~mm} / \mathrm{mm}$. Minimum strain appears along the axis and maximum along the periphery. This may be due to strain hardening at the teeth entrance.

Similarly stress lies within the range of 0 to $59.2 \mathrm{MPa}$. Minimum and maximum stresses appear along the same boundary conditions as strain.

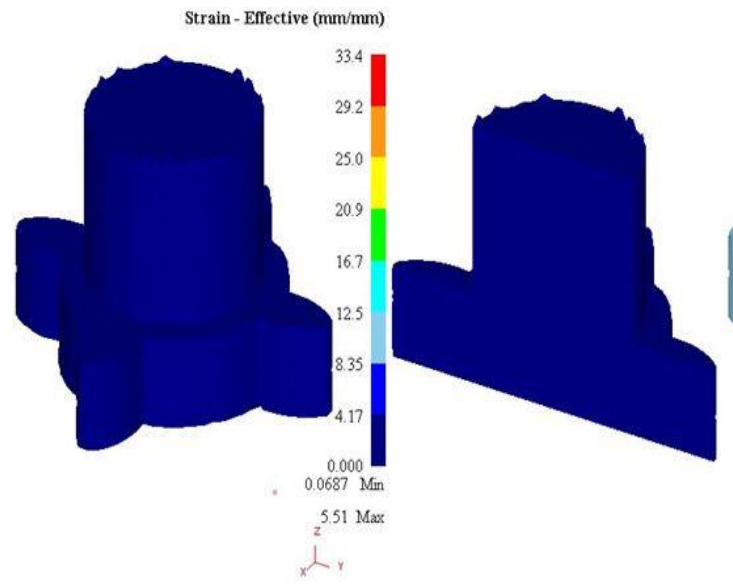

(a) Strain effective for 4 teeth and $15 \mathrm{~mm}$ thick

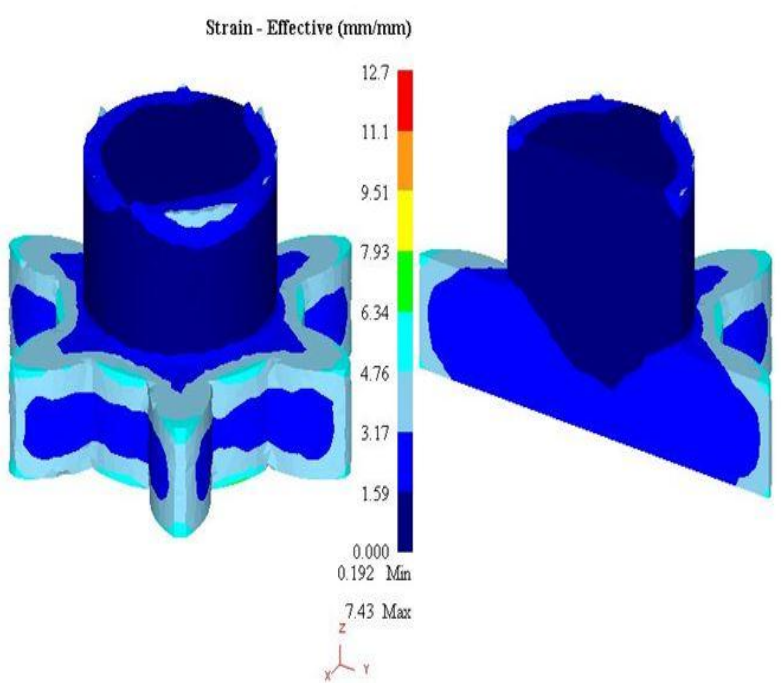

(c) Strain effective for 6 teeth and $15 \mathrm{~mm}$ thick

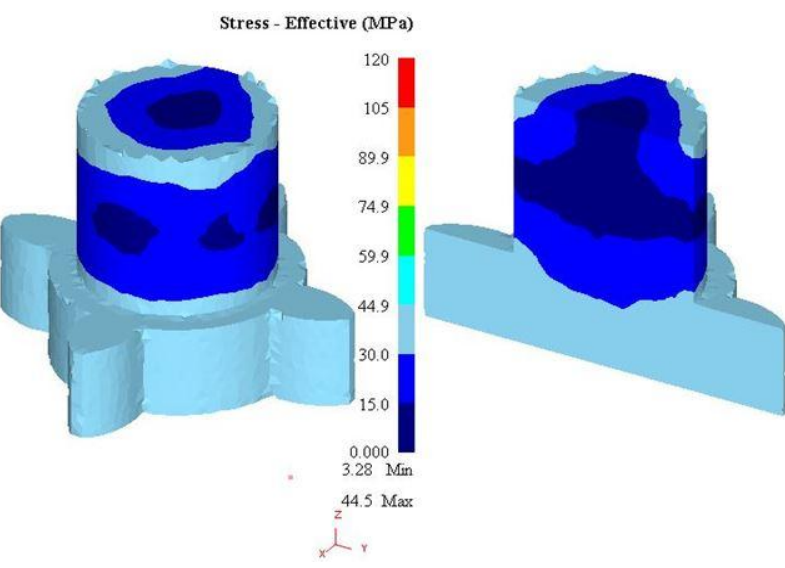

(b) Stress effective for 4 teeth and $15 \mathrm{~mm}$ thick

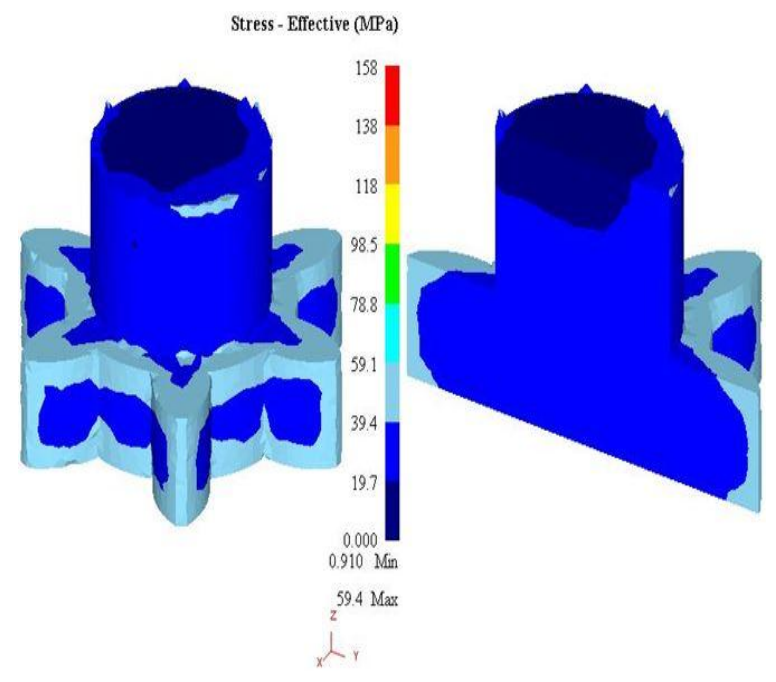

(d) Stress effective for 6 teeth and $15 \mathrm{~mm}$ thick 


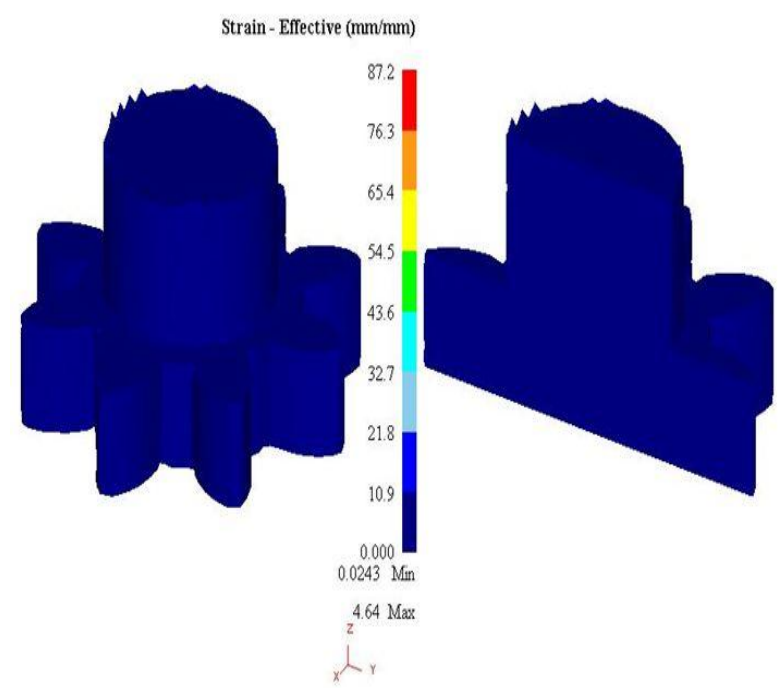

(e) Strain effective for 8 teeth and $15 \mathrm{~mm}$ thick

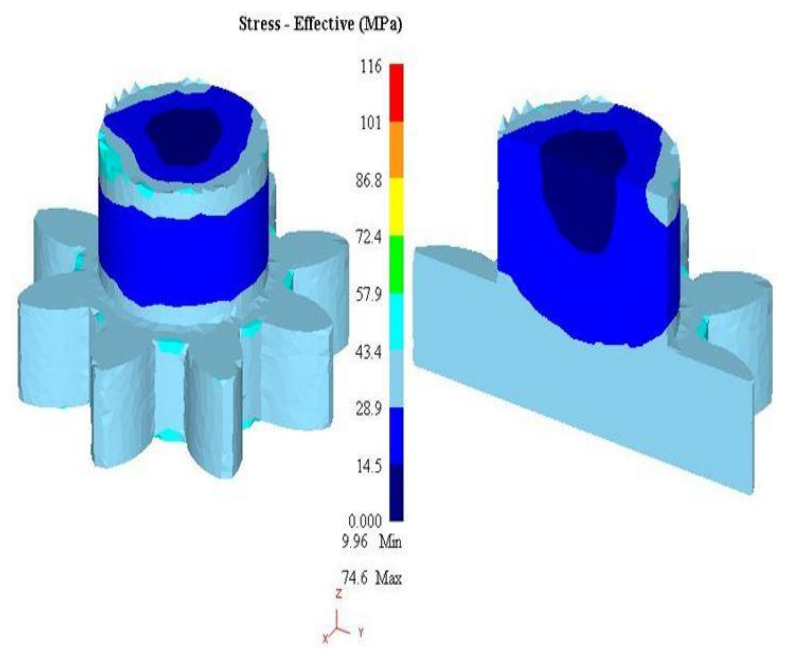

(f) Stress effective for 8 teeth and $15 \mathrm{~mm}$ thick

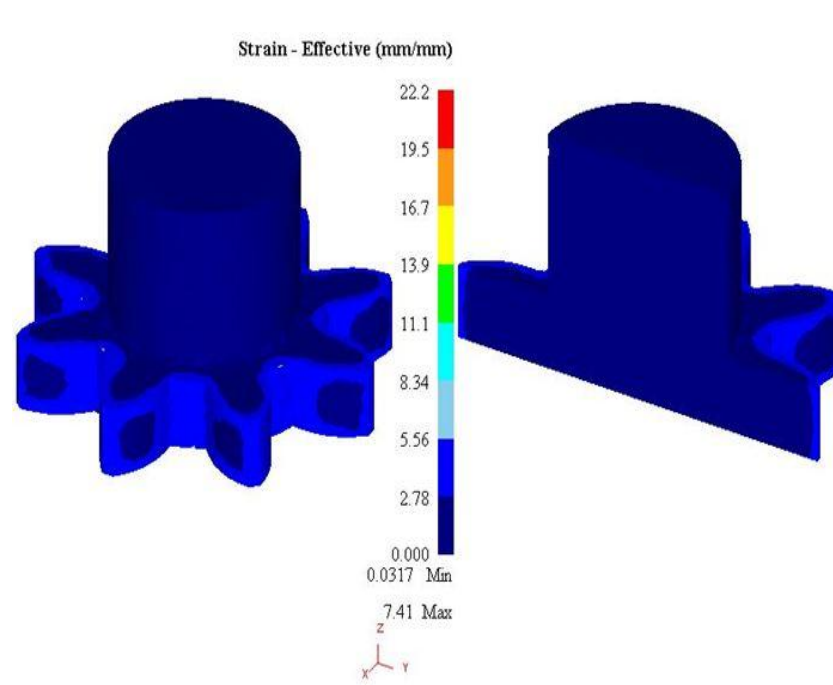

(g) Strain effective for 8 teeth and $10 \mathrm{~mm}$ thick

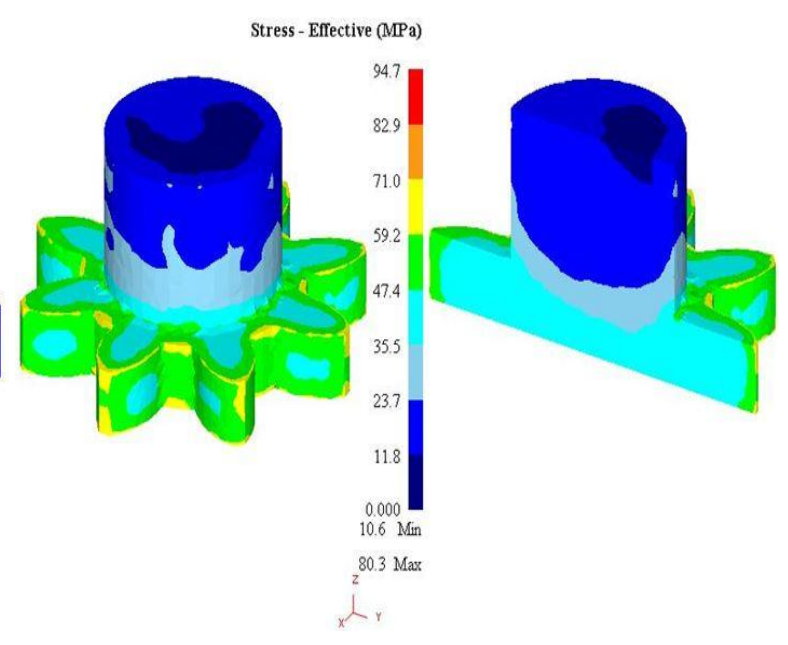

(h) Stress effective for 8 teeth and 10mm thick

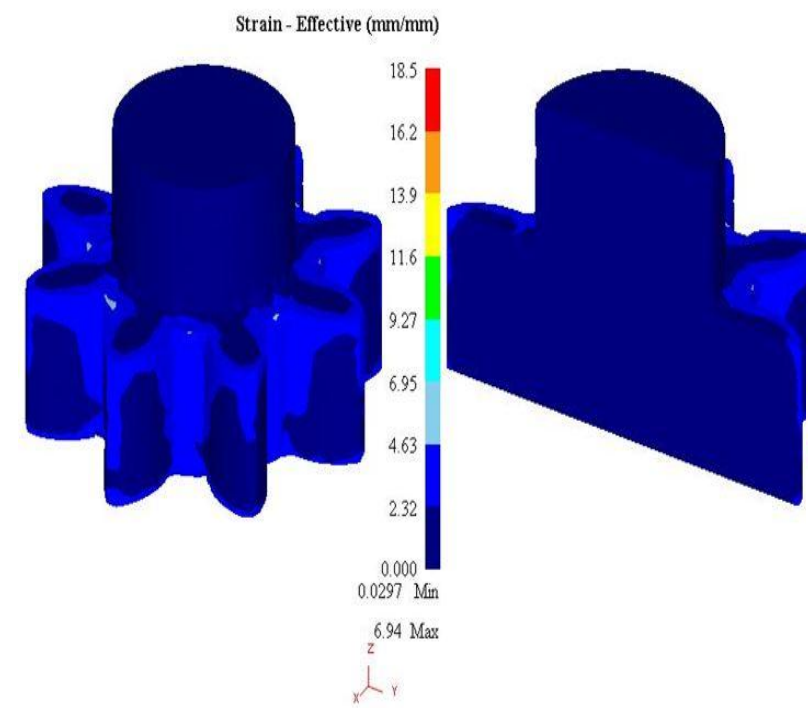

(i) Strain effective for 8 teeth and $20 \mathrm{~mm}$ thick

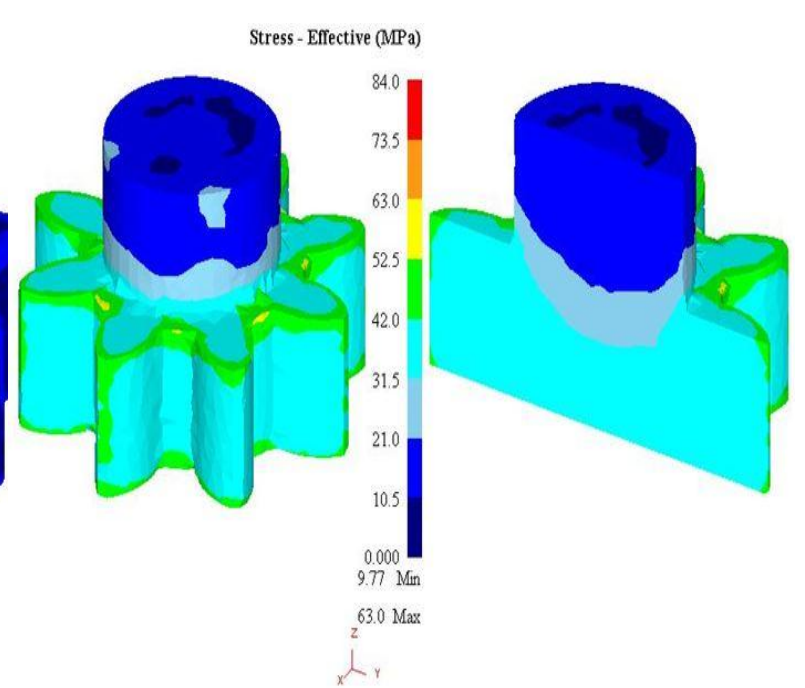

(j) Stress effective for 8 teeth and 20mm thick

Figure 5 Distribution of strain and stress for different geometry of spur gear 
In the second stage, simulations were also carried out for 8-teeth with 10 and $20 \mathrm{~mm}$ teeth thickness as in Fig. 5(g, h, i and j).This is done so as to analyze the effective strain and stress with fixed number of teeth and varying thickness. It is observed that, with increase in thickness from 10 to $20 \mathrm{~mm}$, the maximum value of stress effective decreases. This is due to the fact of less resistance against metal flow. It is also observed from the strain distribution that effective strain is maximum at minimum teeth thickness (for $10 \mathrm{~mm}$ teeth thickness) due to high strain rate.

\subsection{Comparison of results}

\subsubsection{Extruded spur gears}

Comparing the simulation and experimental extruded products shown in Fig. 6, there seems to be good qualitative agreement between them both in shape and size.

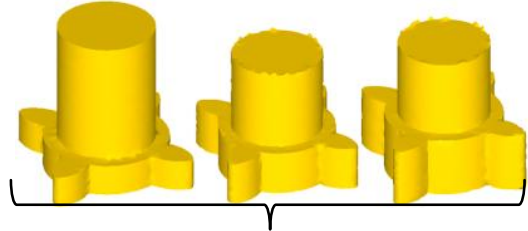

4 teeth, $\mathrm{t}=10,15$ and $20 \mathrm{~mm}$

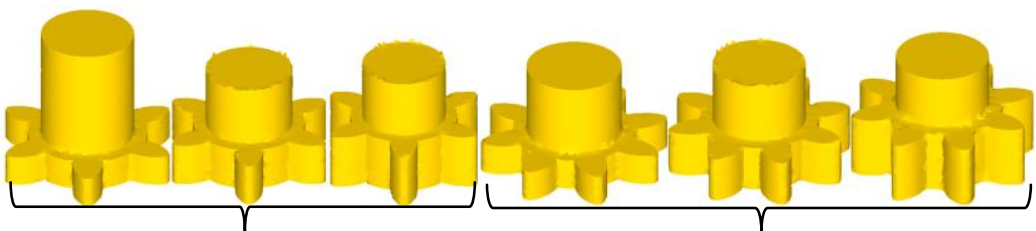

6 teeth, $\mathrm{t}=10,15$ and $20 \mathrm{~mm}$

(a) Extruded spur gear from simulation

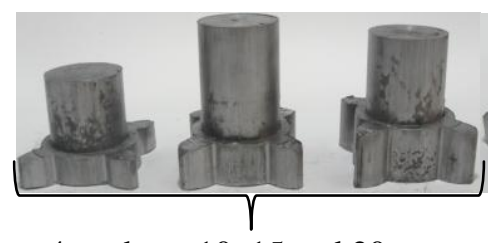

4 teeth, $\mathrm{t}=10,15$ and $20 \mathrm{~mm}$

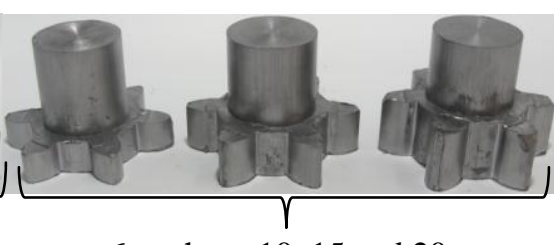

6 teeth, $\mathrm{t}=10,15$ and $20 \mathrm{~mm}$

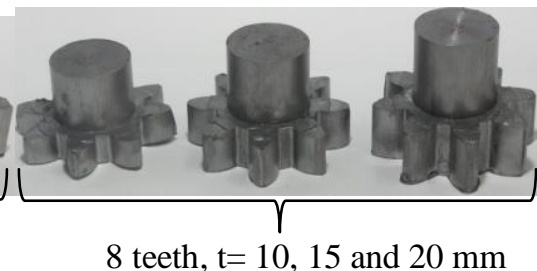

8 teeth, $\mathrm{t}=10,15$ and $20 \mathrm{~mm}$

(b) Extruded spur gear from experiment

Figure 6 Extruded spur gears

\subsubsection{Variation in extrusion loads with punch movement and die shape}

Fig. 7 (a), illustrates that load versus displacement curve can be sub-divided into five principal stages namely: (i) initial compression stage (OA) in which the load increases with very nominal punch displacement, (ii) initial steady-state stage $(\mathrm{AB})$ in which the load almost remains constant, (iii) initial forming stage (BC) where material begins to flow into the teeth cavity, (iv) final steady state stage (CD) where the steady state flow of material takes place inside the teeth cavity and (v) final forming stage (DE) where abrupt increase in load is required to fill the teeth cavity. Similar stages are observed in Fig. 7 (b and c). The constant load in the steadystate stage is due to the fact that actual extrusion takes place during this stage and there is an increase of load due to increase of frictional spread area. This process continues till the metal touches the boundary of the teeth profile. 


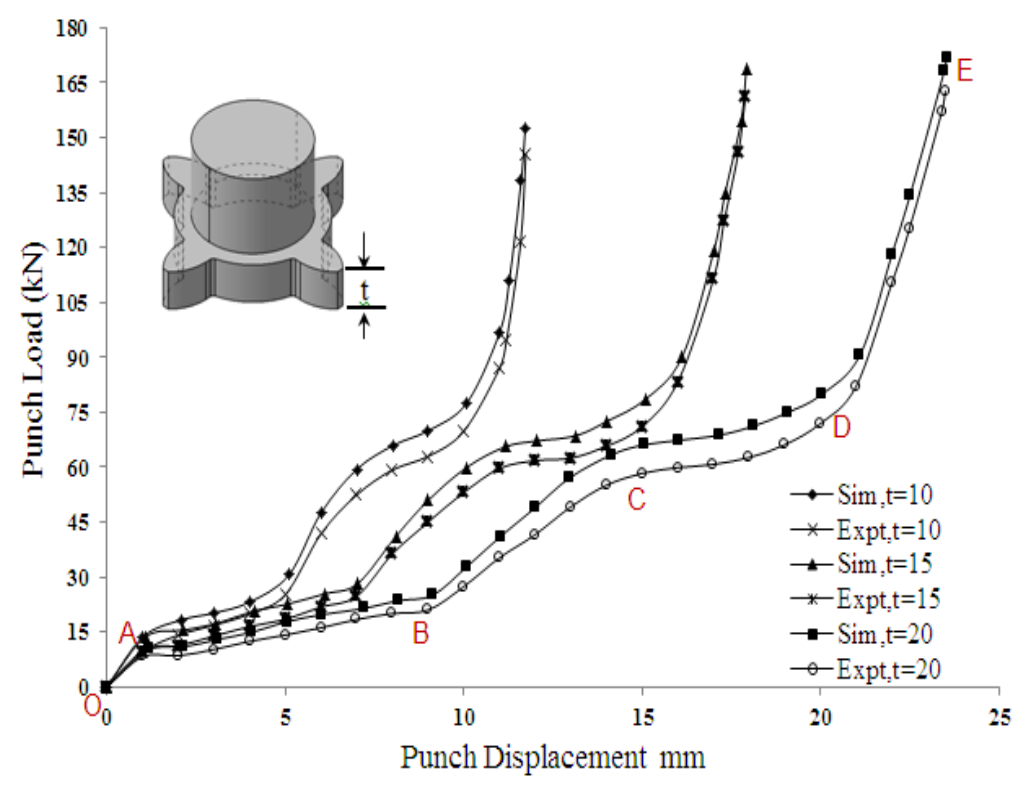

(a) Punch load $\sim$ displacement with varying teeth thickness (4 teeth spur gear)

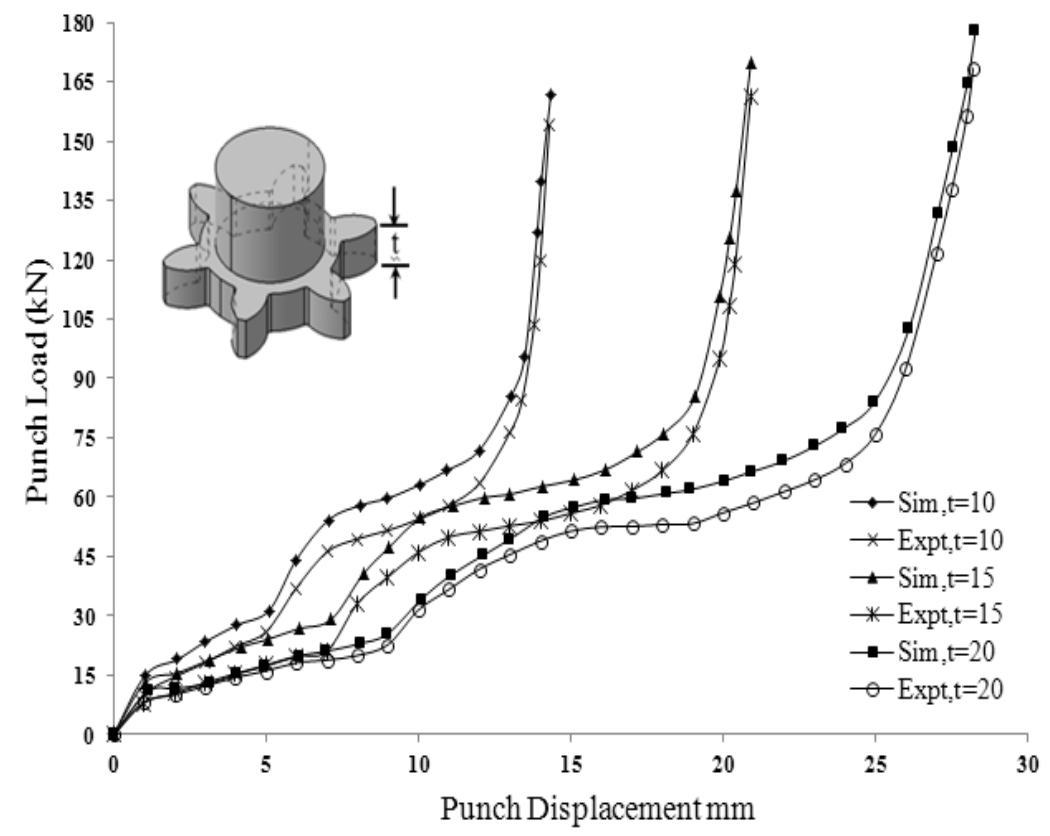

(b) Punch load $\sim$ displacement with varying teeth thickness (6 teeth spur gear) 


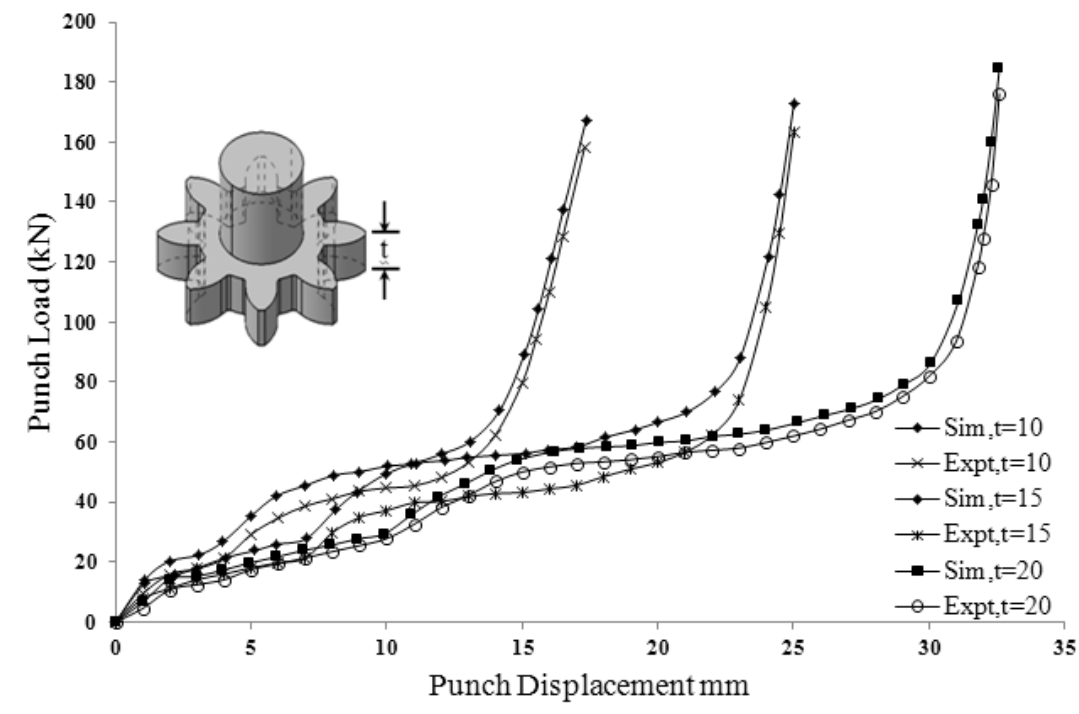

(c) Punch load $\sim$ displacement with varying teeth thickness (8 teeth spur gear)

Figure 7 Variation of punch loads for different spur gears

Table 2 Comparison of peak loads in lateral extrusion of spur gears

\begin{tabular}{|c|l|l|l|l|}
\hline \multicolumn{5}{|c|}{ Spur Gear Head } \\
\hline Nos. of teeth & Thickness (t), mm & Simulation Load $(\mathrm{kN})$ & Experimental Load $(\mathrm{kN})$ & $\%$ Error \\
\hline 4 & 10 & 152.63 & 145.6 & 4.6 \\
\hline 4 & 15 & 168.94 & 161.3 & 4.5 \\
\hline 4 & 20 & 171.93 & 162.67 & 5.3 \\
\hline 6 & 10 & 161.65 & 154.05 & 4.7 \\
\hline 6 & 15 & 169.95 & 161.21 & 5.1 \\
\hline 6 & 20 & 177.28 & 168.35 & 5.03 \\
\hline 8 & 10 & 167.38 & 158.36 & 5.3 \\
\hline 8 & 15 & 172.8 & 163.3 & 5.4 \\
\hline 8 & 20 & 184.45 & 176.14 & 4.5 \\
\hline
\end{tabular}

It is observed that the peak load variations between experiments and FE simulation lies within $5.4 \%$ and the peak load increases with increase in the number of teeth and thickness of the teeth profile as shown in Table 2. In each case, it is also found that the peak load in FE simulation is more than the experimental value.

\subsubsection{Die filling and flow patterns}

Progressive change in shapes of extruded products at different punch movement for both simulation and experimental are shown in Fig. 8. As an illustration, Fig. 9 shows the photograph of the material flow pattern for lateral extrusion of spur gear head section at different punch movement for both in FEM analysis and experimental investigation.
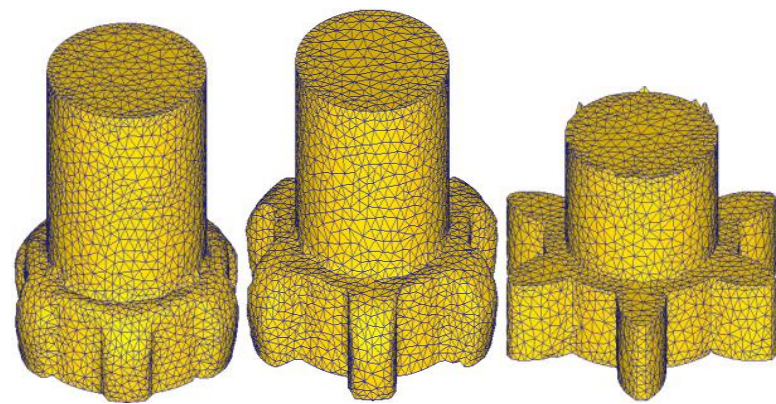

(a)Simulation 


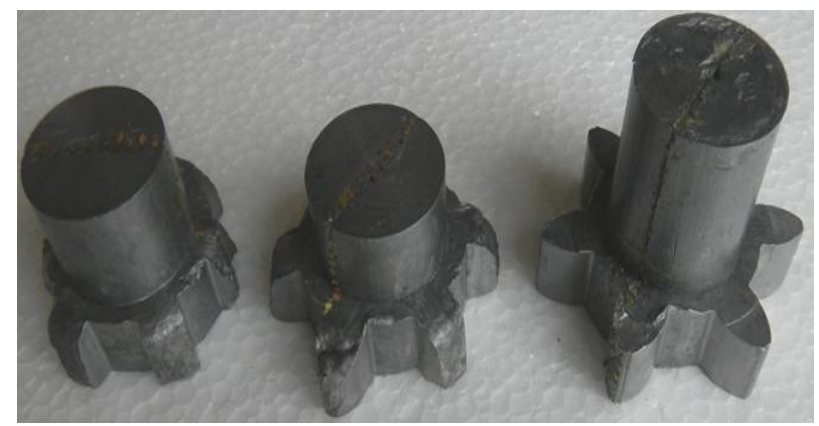

(b)Experiment

Figure 8 Progressive change in teeth profile

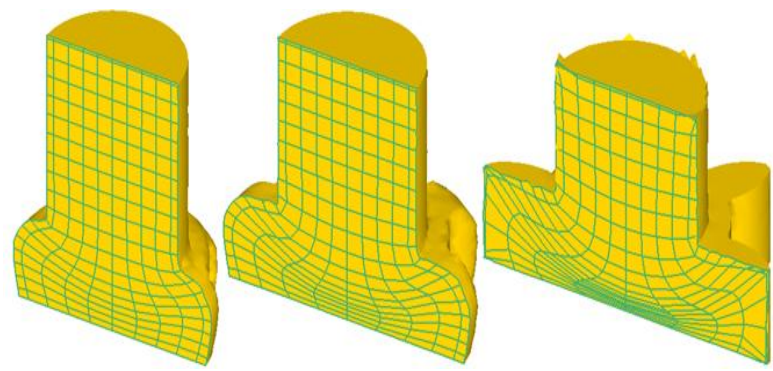

(a)Simulation

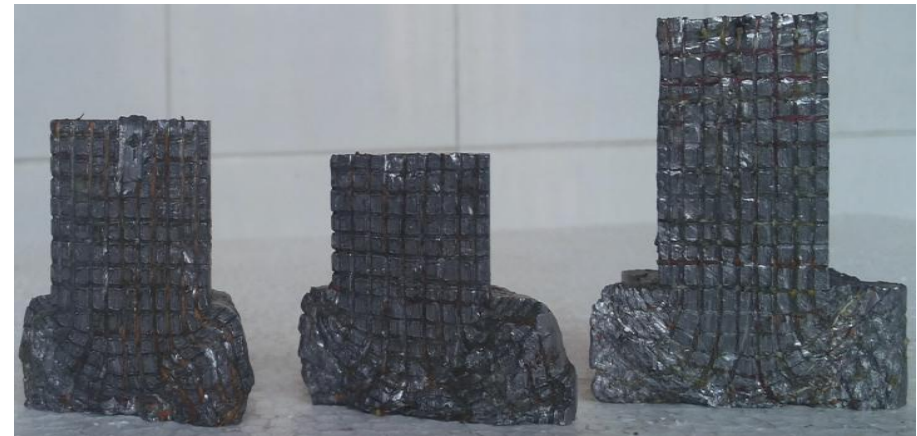

(b)Experiment

Figure 9 Material flow

The gridlines distortion indicates that the process utilizes the maximum amount of redundant work to create the teeth part of the extruded product. It is also clarified that the teeth filling takes place first at the bottom of the die and then the flow proceeds towards the top corners of the die.

\section{CONCLUSION}

The FE simulations for the present work have been carried out to study the various process variables. A series of experiments have been work out to validate the results obtained from FEM. Based on the above discussion, following conclusions have been derived.

1. Effective strain is more at the periphery of the teeth than at the central boss of the cavity.

2. Effective stress is uniform throughout the gear cavity and maximum value is observed at the edges of the teeth.

3. From the load $\sim$ displacement graph it is seen that the forming load increases with increase in thickness and nos. of teeth.

4. It may be concluded from the flow net diagram that the flow of material takes place from the axial line towards the edges of the teeth profile and then towards the corners from bottom to top. During the filling of the teeth, load increases abruptly.

The simulation results qualitatively agree with the experimental results in each of the analyses and hence there is a scope to validate the work quantitatively. 


\section{REFERENCES}

[1] R. Balendra and Y. Qin, Injection forging: engineering and research, Journal of Material Processing Technology, 145, 2004, 189-206.

[2] N. R. Chitkara and A. Aleem, Axi-symmetric tube extrusion/piercing using die mandrel combinations: some experiments and a generalized upper bound analysis, International Journal of Mechanical Science, 43, 2001, 1685-1709.

[3] F. Dohmann and M. Laufer, Working accuracy of toothed extrusion dies, Advance Technology Plasticity $I, 1990,335-341$.

[4] I. Moriguchi, Cold forging of gears and other complex shapes, Journal of Material Processing Technology, 35, 439-450 (1992).

[5] N. A. Abdul and T. A. Dean, An analysis of the forging of spur gear forms, International Journal of Machine Tools Design and Research, 26(2), 1986, 113 -1 23.

[6] K. Ohga, K. Kondo and T. Jitsunari, Research on precision die forging utilizing divided flow, Bull. JSME 28(244), 1985, $2451-2459$.

[7] K. Kondo and K. Ohga, Development of precision cold die forging process utilizing divided flow, $J$. JSTP 27(300), 1986, 121-131.

[8] K. Ohga and K. Kondo, Research on application of the precision cold die forging utilizing divided flow to thick products, Advance Technology Plasticity Il , 1993, 1239-1244.

[9] N. R. Chitkara, M. A. Bhutta, Near-net shape forging of spur gear forms: an analysis and some experiments. International Journal of Mechanical Science, 38, 1996, 891-916.

[10] N. R. Chitkara and K. Yohngjo, An analysis of external spline gear forming by an upper bound energy method, International Journal of Mechanical Science, 38, 1996, 777-89.

[11] H. H. Hsu, A study on precision forging of spur gear forms and spline by upper bound method, International Journal of Mechanical Science, 44, 2002, 1543-1558.

[12] J. C. Choi, Y. Choi, K. D. Hur and C. H. Kim, A study on the forging of spur gears, International Journal of Mechanical Science, 38, 1996, 1333-1347.

[13] H. Cho, J. Choi, G. Min and Y. Choi, An upper bound analysis of the closed-die forging of spur gears Journal of Material Processing Technology, 67, 1997, 83-91.

[14] J. Choi, H. Y. Cho and C. Y. Jo, An upper-bound analysis for the forging of spur gears. Journal of Material Processing Technology,104,2000, 67-73.

[15] M. L. Alves, J. M. C. Rodrugues and P. A. F. Martins, Cold forging of gears: experimental and theoretical investigation, Finite Element Analysis and Design, 37, 2001, 549-558.

[16] R. Balendra, Injection-chamber to die-cavity interface for injection forming, International Journal of Machine Tool Manufacturing, 33 (6), 1993, 753-760.

[17] R. Balendra, Considerations in the modeling of injection upsetting, Int. J. Prod. Res. 25, 1987, 889-906.

[18] Y.S. Lee, S.K. Hwang, Y.S. Chang and B.B. Hwang, The forming characteristics of radial forward extrusion, Journal of Material Processing Technology 103, 2001, 136-140.

[19] O. P. Grover and B. J. Juneja, Analysis of closed-die forging of gear-like elements, Adv Tech Plast II, 1984, 888-893.

[20] Y. Can, T. Altinbalik and H. E. Akata, A study of lateral extrusion of gear like elements and splines, Journal of Material Processing Technology, 166(2005), 128-134.

[21] Scientific Forming Technologies Corporation. DEFORM3 Manual, Version V8.1, Scientific Forming Technologies, (Corporation, Columbus, OH, 2005). 